\title{
Ledhug: Syncretic Music Culture in Magetan
}

Ledhug: Sinkretisme Budaya Musik di Magetan

\author{
Dea Lunny Primamona \\ Penerima Beasiswa LPDP (Lembaga Pengelola dana Pendidikan) \\ Jl. Cikini Raya No.91 Jakarta 10330 \\ e-mail: dealunny@gmail.com; Cp. 085708508521 \\ Dolly Nofer \\ Pascasarjana Universitas Sebelas Maret Surakarta \\ J1. Ir. Sutami No. 36 A, Surakarta, Indonesia 57126 \\ e-mail: dolly.nofer@gmail.com; Cp. 081393558516
}

Cite this article: Primamona, Dea Lunny \& Nofer, Dolly. 2019. "Ledhug: Syncretic Music Culture in Magetan". Dewaruci: Jurnal Pengkajian dan Penciptaan Seni, Volume 14/2: page 112

\begin{abstract}
In Magetan, East Java, Indonesia, the turn of the Javanese and Islamic years is marked by the celebration of Ledhug Sura. The celebration consisted of various events such as the Ledhug music festival, the people's market, the carnival, the night of repentance and the climax at the Andum Berkah Bolu Rahayu procession. This is a carnival for cakes and agricultural products which are considered to bring blessings to the community. This research focuses on the ledhug (lesung and bedhug, which means a combination of mortar and drum) music festival. Mortar and bedhug are the main focus of this article. The purpose of this study is to (1) reveal the form of the conception of ledhug music and (2) recognize the concepts contained in the ledhug music.

Data mining methods include fieldwork using observation and interview techniques; literature review; and data presentation methods using descriptive-interpretative techniques. Based on the results of fieldwork and reading or interpretation of the ledhug music culture, it was concluded that the ledhug music performance was the result of a process of cultural syncretism. Ledhug music culture exists as a blend of musical elements from Javanese and Islamic music culture.

Cultural syncretism in the context of ledhug is a deliberately produced discourse building, namely as a form of resolution of the reality of cultural contestation between the two ideologies that existed in Magetan.
\end{abstract}

Keyword: ledhug, lesung, bedug, sinkretisme, dan musik

\section{Pendahuluan}

Musik secara metafisis mempunyai realita di balik apa yang teraba oleh inderawi kita. Sebab, musik dikatakan sebagai: (1) hasil dari nilai-nilai, sikap, dan kepercayaan manusia (Merriam 1964, 6); (2) alat komunikasi sehingga dapat digunakan untuk memahami kebudayaan, dan bahkan ada yang mengatakan bahwa musik adalah bahasa universal (Merriam 1964, 10-13); (3) sebuah sistem (Merriam 1964, 29); dan (4) 
perilaku simbolis (Merriam 1964, 229). Secara sederhana musik menjadi bermakna atau signifikan oleh karena adanya aspek fungsi dan guna. Wade menyatakan, betapapun ramainya perdebatan tentang entitas musik, manusia membuat musik begitu berarti baik secara individual maupun komunal (Wade 2004, 10).

Ledhug menempati posisi di antara "berlaksa-laksa" pertunjukan musik di dunia, yang memiliki arti tersendiri bagi pemilik budayanya yakni masyarakat Magetan. Ledhug ditakrifkan sebagai perpaduan musik antara lesung dan bêdhug yang menjadi tradisi dalam menyambut tahun baru Saka dan Hijriyah, yang jatuh pada awal bulan Sura dan Muharram. Ledhug dicetuskan oleh Mamiet Slamet (alm.) di tahun 2003 (wawancara Suminah 2012). Inisiasi ini kemudian disambut dan digarap oleh beberapa orang yang tergabung dalam sebuah tim. Seiring berjalannya waktu, ledhug menjadi perhelatan annual yang kemudian membentuk pemaknaan khusus oleh masyarakat. Lesung dan bêdhug di dalam tradisi ledhug diberi sebutan lesung Sura dan bêdhug Muharram (Muljono 2003).

Tradisi ledhug sudah berlangsung hampir dua dekade, dengan format penyelenggaraan yang berbeda-beda dari tahun ke tahun. Namun, terdapat suatu konsepsi ide yang tetap dipertahankan dalam kelangsungan tradisi ledhug tersebut. Konsep ledhug tercermin dalam kompleksitas isi pertunjukannya. Untuk itu penulis menarik rumusan masalah dalam tulisan ini sebagai berikut: (1) Bagaimanakah wujud konsepsi musik ledhug itu? dan (2) Apa yang direpresentasikan oleh wujud konsepsi musik ledhug tersebut? Pertanyaan ini sangat urgen karena penulis melihat antusias masyarakat dalam mengapresiasi tradisi musik ledhug. Asumsi penulis, musik ledhug lebih dari sekadar produk dalam rangka perayaan tahun baru, namun wujud dari upaya sinkretisme dalam media musik, dan wujud representasi cita-cita masyarakat Magetan secara umum.

\section{Pembahasan}

\section{Ledhug: Lesung dan Bedhug}

Sinkretisme adalah suatu proses memadukan atau mengharmomisasikan beberapa paham (dapat berupa aliran-aliran agama atau kepercayaan), sehingga menghasilkan bentuk abstrak yang baru dan berbeda untuk mencari keserasian, dan keseimbangan (Saksono dan Wicoyo 2019, v). Ledhug merupakan gabungan dua simbol paham Jawa dan paham Islam. Paham ke-Jawa-an dapat ditemui di empat belas aliran kepercayaan yang statusnya sebagai minoritas (wawancara Suminah 2012). Sedangkan paham ke-Islam-an dapat ditemui sebagai agama mayoritas di Magetan. Singkatnya, lesung dianggap dapat mewakili idiom ke-Jawa-an dan bêdhug mewakili idiom keIslam-an. Dengan demikian, ledhug dapat dikatakan sebagai upaya sinkretis kebudayaan, mewakili Jawa dan Islam di Magetan.

Sebagai suatu sistem tanda-relasi sesuatu pada sesuatu yang lain, bunyi kata 'lesung' dan 'bêdhug', dan mimesis bunyinya dapat mengarahkan ke realitas konsep yang menjelaskan setiap penanda tersebut di dalam benak masyarakat.

\section{Konsep Lesung}

Kata 'lesung' dalam kedudukan sebuah frasa (seperti pada perahu 'lesung' (Koentjaraningrat 1990, 273), lesung pipit, dan Tanjung Lesung (nama sebuah tempat)), merujuk pada suatu sifat atau ciri tertentu. Lesung menunjuk kepada suatu bentuk fisik yang memiliki sisi cekung atau berlubang. Lesung dalam konteks budaya masyarakat 
Magetan dikenali dalam sepasang piranti atau alat lesung dan alu. Lesung dan alu digunakan untuk menumbuk padi yang telah dipotong menggunakan ani-ani. Lesung pada jamannya tersebar hampir di seluruh wilayah agraris Nusantara dengan rupa bentuk, bahan, ukuran, warna, dan nama yang berbeda-beda.

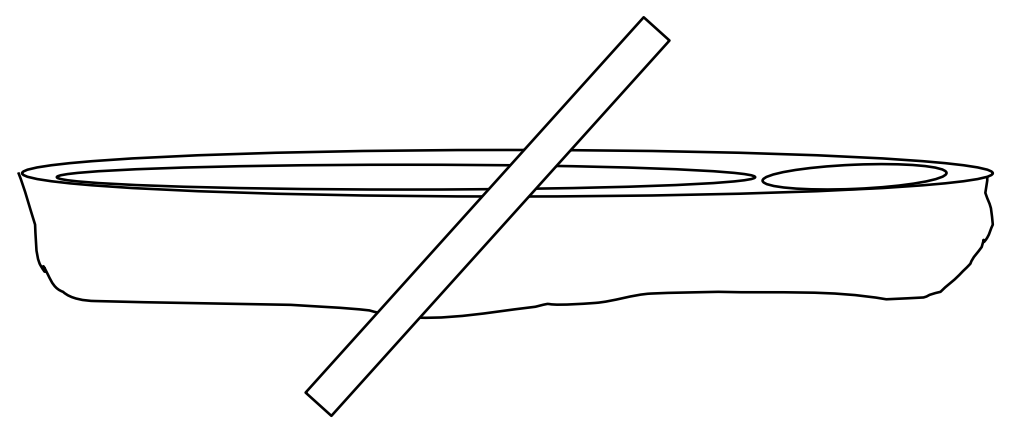

\section{Gambar 1. Gambaran wujud lesung dan alu atau antan}

Dalam pengaruh Hinduisme, masyarakat Jawa memaknai lesung dan alu sebagai simbol kesuburan (lingga-yoni) (Peters dan ASEAN Committee on Culture and Information 2003, 163). Artefak yang memperkuat fakta tersebut didapati pada Candi Sukuh, Karanganyar, Jawa Tengah. Beberapa penelitian juga menerangkan tentang korelasi kosmos dengan melihat garis vertikal dan horizontal pada lesung dan alu (Sunoto 2017, 157). Garis tersebut menandakan hubungan vertikal manusia dengan Tuhannya maupun hubungan horizontal manusia dengan alam dan sesamanya. Lesung di dalam praktik berladang, melahirkan nilai kebersamaan dan gotong-royong. Masyarakat agraris pra-modern menumbuk padi secara bersama-sama dengan menggunakan kedua alat tersebut. Terkadang bunyi yang muncul dari tetabuhan lesung disertai gerakan dan nyanyian, dapat mengobati kejenuhan dan kepayahan saat bekerja di ladang (wawancara Suminah 2012, Soetardjono 2014). Pola-pola tabuhan yang beragam tersebut dikenal dengan sebutan gendhing lesung. Gendhing-gendhing tersebut antara lain Asu Gancet, Wayangan, Blendrong, Bengah Singo, Kutut Manggung, Kupu Tarung dan lain-lain.

Dalam pengaruh pendewasaan teknologi oleh pemerintah pada era orde baru, lesung mulai tergantikan dengan mesin perontok kulit padi (rice mill). Mesin perontok padi tersebut mengedepankan efisiensi waktu dan tenaga, dan menukar kebersamaan dan gotong royong dalam bentuk yang lain. Dampaknya, budaya menumbuk padi dengan bernyanyi bersama-sama akhirnya mulai ditinggalkan secara perlahan.

Penerimaan masyarakat terhadap mesin perontok ini juga sempat diwarnai dengan sentimen-sentimen negatif dari masyarakat. Terutama bagi masyarakat yang mewarisi paham bahwa padi adalah bentuk lain dari seorang dewi. Mesin perontok padi dianggap melukai dewi yang mereka sebut sebagai Dewi Sri yang berwujud padi, yang sebelumnya diperlakukan secara khusus. Dengan demikian, eksistensi lesung berkaitan dengan sistem nilai masyarakat yang kompleks dengan budaya tutur dan pola keseharian masyarakatnya.

Di Magetan yang sebagian wilayahnya masih hijau dan asri tidak dapat menghindari kenyataan budaya baru. Walaupun sebagian besar masyarakatnya bermatapencaharian sebagai petani dan bergantung pada sektor ekonomi mikro, namun demikian sebagian besar masyarakatnya kini tidak mengenal lesung sebagai produk kebudayaan atau bagian hidup mereka. Kebudayaan berubah, pola hidup masyarakatpun 
berubah. Keterjarakan budaya ini tidak hanya ditengahi oleh waktu, namun juga dikarenakan bertambahnya kesadaran-kesadaran baru dalam masyarakat yang menghasilkan sikap kultural tertentu.

\section{Konsep Bêdhug}

Bêdhug saat ini masih sering ditemui di dalam tempat peribadatan umat Muslim di Magetan. Bêdhug berfungsi untuk mengkomunikasikan lima waktu sholat (subuh, dzuhur, ashar, magrib dan isya). Seorang muadzin menabuh bêdhug dan mengumandangkan suara adzan, agar pesan dapat diterima oleh warga Muslim yang terjangkau di sekitarnya.

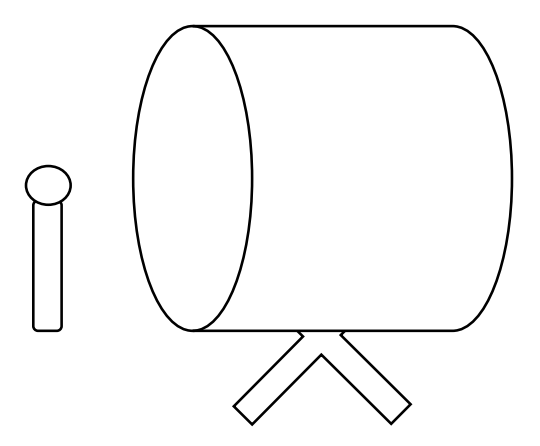

Gambar 2. Ilustrasi bentuk bêdhug dan pemukulnya.

Bêdhug terbuat dari balok kayu yang mempunyai rongga sehingga bagian badannya berbentuk tabung berongga, dan mempunyai dua kutub membran yang terbuat dari kulit binatang. Bêdhug menurut masyarakat dibawa oleh dari para wali saat menyebarkan agama Islam di tanah Jawa (wawancara Suminah 2012, Sukadi 2012, Soetardjono 2014). Dengan demikian, bêdhug dianggap suci dan sakral.

Semua aktivitas manusia yang bersangkutan dengan religiusitas, berdasar pada suatu getaran jiwa yang biasanya disebut emosi keagamaan. Emosi inilah yang juga mendorong manusia memberi predikat sakral atau suci di dalam tindakan-tindakan, gagasan-gagasan dan juga benda-benda (Koentjaraningrat 1990, 295). Emosi keagamaan sifatnya hanya sesaat, dan dijaga sedapat mungkin di antara pemeluk agama (Koentjaraningrat 1990, 295). Bêdhug dijadikan sarana dalam mencapai emosi keagamaan tersebut, sehingga keberadaannya harus terus dipertahankan. Untuk itulah bêdhug dianggap sebagai benda sakral di dalam peribadatan umat Muslim di Magetan karena posisi dan nilai historis yang diyakininya.

\section{Citra dari Fenomena Bunyi}

Masyarakat Magetan mengenal istilah 'klothékan' yang merujuk pada citra bunyi lesung. Istilah lain yang berkembang di daerah di luar Magetan, juga mengenal istilah 'kothékan' dan 'gojêg' untuk menunjukan citra bunyi yang sama. Dalam terminologi linguistik Ferdinand de Saussure, dapat kita lihat seluk-beluk hubungan dalam tanda yang diaktualisasikan dalam model berikut ini: 


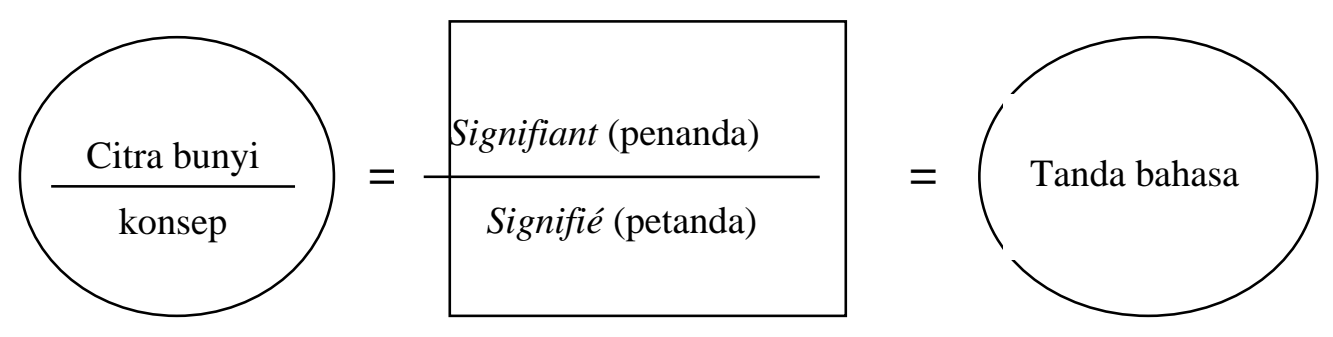

Gambar 3. Model tanda bahasa Saussure.

Hubungan antara penanda dan petanda biasanya bersifat arbitrer. Tidak ada alasan logis mengapa citra bunyi 'klothékan' dihubungkan dengan konsep lesung. Dalam analisis, proses penandaan berawal dari fenomena onomatope. Bunyi 'thék' dipahami sebagai bunyi yang dihasilkan oleh pukulan lesung. Perubahan bentuk menjadi kata 'klothék', dipahami untuk menunjukan realitas bunyi yang lebih dari satu atau bertalu-talu. Sedangkan penambahan imbuhan '- an' di belakang kata tersebut untuk menunjukan sifat kebendaan.

Sementara itu, citra bunyi kata bêdhug yang sudah terlebih dulu mencitrakan konsep bêdhug melalui fenomena onomatope 'dhug'. Penamaan dari fenomena bunyi 'dhug' menjadi 'bêdhug ', diduga karena suara yang dihasilkan dalam satu pukulan menghasilkan residu bunyi. Fenomena onomatope tidak dapat lepas dari konvensi sosial. Bunyi bêdhug tercitra di dalam benak masyarakat akibat kehadirannya yang repetitif dan berkelanjutan. Dengan demikian, masyarakat Magetan tidak asing lagi mendengar bunyi atau suara kedua instrumen lesung dan bedhug.

\section{Identifikasi Konsep Musikal Ledhug dan Konteksnya}

Ledhug merupakan garapan musik baru dan sampai saat ini garapannya terus mencari bentuk yang "mapan". Aspek musikalitas dari masing-masing unsur baik itu lesung dan bedhug telah dicabut dari akar budayanya. Lesung tidak lagi dikenal dengan sebutan gendhing Kupu Tarung, Asu Gancet, Bengah Singo, Kutut Manggung, dan sebagainya. Namun demikian, ada beberapa kelompok seniman lesung yang terus mempertahankan pola-pola bentuk dan ritme yang telah bertahan lama. Sementara itu bedhug ditabuh tidak dengan disertai lantunan adzan. Keberadaan pola lama maupun pola baru kedua isntrumen, dapat dikatakan memiliki intensi yang sama, yakni mempertahankan atau melestarikan eksistensi.

Unsur-unsur bunyi di dalam lesung dan bêdhug digabungkan dalam suatu penataan artistik bunyi yang otoritasnya dipegang oleh kelompok-kelompok kesenian baru. Secara teknis seperti durasi, jumlah pemain dan instrumen yang ditambahkan dalam suatu ensamble ditentukan oleh pihak penyelenggara Festival Musik Ledhug. Hal itu dapat diamati pada sebuah dokumen ("Pedoman Pelaksanaan (Domlak) Festival Musik Lesung dan Bedhug dalam Rangka 1 Suro 1946 tahun Saka - 1 Muharram 1434 H Kabupaten Magetan Tahun 2012" 2012). Berikut merupakan analisis general dari penyajian komposisi musik ledhug yang dimainkan oleh beragam kelompok kesenian di Magetan.

\section{Instrumentasi}

Pemilihan instrumen dipengaruhi oleh aturan main panitia penyelenggara. Lesung dan bêdhug menjadi instrumen utama, di samping vokal, saron, demung, 
kendang, dan intrumen non-elektrik lainnya. Keduanya berfungsi sebagai instrumen perkusif.

Lesung dan bêdhug memiliki tipikal bunyi yang berbeda. Hal itu dipengaruhi sistem organologi serta teknik dan daya pukul. Organologi dari instrumen tersebut membedakan dan mencirikan bunyi yang satu dengan yang lainnya. Di catatan lapangan, didapati seorang peserta Festival Seni Pertunjukan Ledhug 2013 secara inisiatif mengangkut lesung dari desanya. Peserta beranggapan bahwa lesung yang disediakan oleh panitia penyelenggara di atas panggung tidak lebih baik kualitasnya dari lesung yang dibawanya, sehingga lesung desa miliknyalah yang digunakan pada saat kelompoknya ini tampil. Dengan demikian, dapat disimpulkan bahwa pemilihan instrumen turut melibatkan pertimbangan-pertimbangan estetis.

Dalam penelitian tentang lesung bahkan tidak hanya organologi secara fisik yang membuat ciri bunyi tersebut, namun ada istilah emik lontas atau kejernihan bunyi yang dipresentasikan oleh kelompok lesung dari Desa Turi. Kejernihan bunyi dicapai dengan beberapa indikator aspek, salah satunya teknik tabuhan alu yang berkaitan dengan titik pukulnya di bagian tertentu lesung.

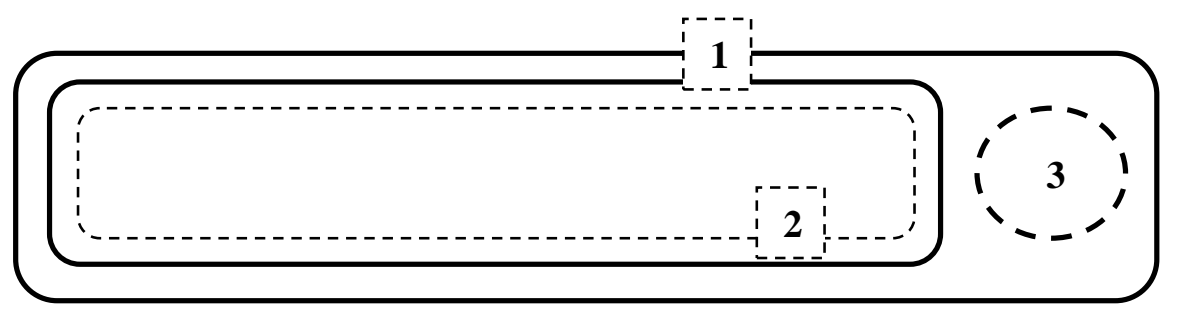

Gambar 4. Ilustrasi ranah pukul pada lesung ditunjukkan dengan garis putus-putus.

Sebagai sebuah instrumen, lesung termasuk ke dalam klasifikasi instrumen idiophone, karena sumber bunyinya terletak pada badan instrumen itu sendiri. Getaran udara yang tercipta untuk menimbulkan bunyi diperkuat dengan adanya resonator berupa cekungan di dalamnya. Karakter bunyinya cenderung berdurasi pendek dan tidak menghasilkan anak suara.

Berbeda dengan lesung, bêdhug mempunyai membran yang terbuat dari kulit binatang di kedua kutub, yang memantulkan getaran udara saat dipukul sehingga bunyi bêdhug cenderung menggema. Elastisitas kulit yang menjadi bagian dari bentuk bêdhug ini membuatnya menjadi pengantar bunyi yang mendukung nada dan panjang getaran yang ingin dicapai.

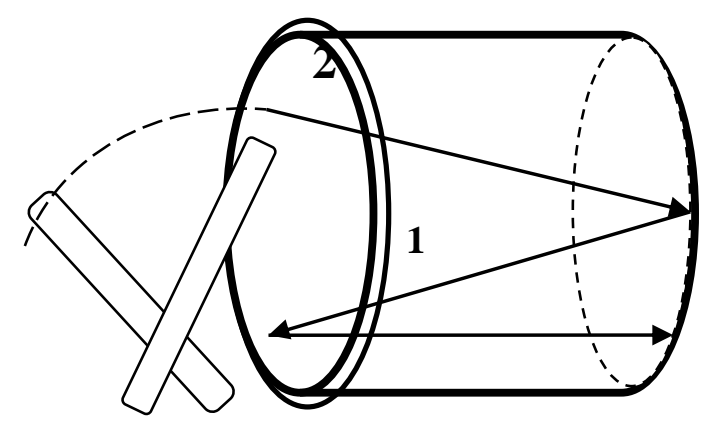

Gambar 5. Getaran udara yang menimbulkan bunyi saat bêdhug dipukul. 
Secara umum tipikal warna suara bêdhug sangat dipengaruhi oleh volume tabung yang menjadi rangkanya, kayu bahan pembuatnya dan ketebalan kulit binatang (Sulisto 1996, 27) yang dijadikan membran. Bêdhug termasuk dalam klasifikasi instrumen membranophone, karena sumber bunyinya berasal dari vibrasi membrannya. Instrumen bêdhug memegang peran seperti halnya instrumen kempul dan gong, yang bermain garap struktural dalam karawitan musik Jawa.

\section{Bentuk dan Struktur Komposisi}

Bentuk dan struktur komposisi musiknya bersifat fleksibel sesuai dengan kreatifitas artistik masing-masing kelompok musik ledhug. Meskipun seharusnya komponis bebas mengekspresikan elemen-elemen musikal, di dalam konteks festival yang dilombakan seniman tidak dapat lepas dari aturan main yang diberikan oleh panitia penyelenggara. Dalam Festival Seni Pertunjukan Ledhug 2012 misalnya, ada aturan mengenai durasi, jumlah peserta dan pelaku musik, latar-belakang, lagu yang dibawakan, dan pembatasan instrumentasi tambahan, bahkan hingga saat tahun 2019 aturan tersebut masih ada. Meskipun demikian, terdapat suatu pola bentuk dan struktur yang tidak berubah dalam setiap komposisi yang dipresentasikan oleh kelompokkelompok musik ledhug. Bentuk umum yang digunakan oleh kelompok kesenian musik ledhug mirip dengan musik populer, pop dan campursari pada umumnya. Strukturnya terdiri dari pembukaan atau introduction, kemudian isi lagu yang dihiasi oleh tarian atau teater, dan kemudian bagian akhir atau outro. Adapun perulangan dilakukan selesai isi lagu seperti halnya musik pop yang memiliki jembatan atau bridge untuk mengulang bagian isi dengan penekanan tertentu. Beberapa kelompok cenderung menggunakan bentuk dan struktur musik yang sudah ada dari referensi musik popular yang sering didengar dalam keseharian. Oleh karena itu, kreatifitas kelompok musik ledhug diidentifikasi cenderung masih memakai bentuk dan struktur musik yang sudah ada daripada melakukan percobaan untuk menemukan dan membuat bentuk dan struktur musik yang berbeda.

\section{Hitungan Dasar Musik}

Dalam festival tersebut diidentifikasi kecenderungan komposisi memakai dasar pemikiran musik karawitan Jawa dan musik barat. Hal ini ditunjukan dalam sistem garap hitungannya, yaitu hitungan habis empat. Hitungan ini dapat dengan mudah diidentifkasi dari musik tonal yang menyertainya misalnya saron atau vokal, dan juga musik atonal yang mempunyai warna suara yang bertekananan berat seperti bedhug atau bagian tertentu dari lesung. Kelompok yang berorientasi musik pada karawitan Jawa menggunakan sistem gatra yang menempatkan down beat atau hitungan berat pada hitungan ke-empat seperti: $\underline{1234} \quad \underline{1234} \quad \underline{1234} \quad 1234$. Sedangkan kelompok yang berorientasi pada konsep musik barat dalam komposisinya menempatkan down beat atau hitungan berat pada hitungan pertama dalam satu birama, seperti ini: | 1234 |

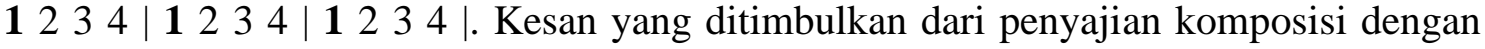
dua hitungan ini sangatlah berbeda.

\section{Sistem Harmonisasi}

Lesung dan bêdhug merupakan instrumen perkusif. Sistem harmoni tidak ditunjukkan dengan sistem akor, karena keduanya merupakan musik atonal. Penataan artistiknya ditunjukkan dengan ritme, dinamika, tempo dan tekstur. Tekstur atau jalinan ritme adalah salah satu sistem harmoni, atau keseimbangan peletakkan warna-warna 
bunyi dalam ritme. Beberapa kelompok kesenian ledhug menyadari bahwa warna bunyi dan kejelasannya sangat penting dalam sebuah komposisi. Teknik interlocking antara kedua instrumen adalah hal dapat diidentifikasi dengan mudah.

\section{Konteks Penyajian Musik Ledhug}

Ledhug dipresentasikan dalam pertunjukan, baik pada saat perayaan tahun baru Saka dan Hijriyah maupun di dalam kepentingan lainnya. Peristiwa pertunjukan merupakan peristiwa sosial yang terancang, dan interaksi sosial yang terjadi ditandai dengan kehadiran secara fisik para pelaku peristiwa di dalam ruang tersebut (Simatupang 1999, 7). Di dalam peristiwa pertunjukan ledhug, komposisi musik yang rapi dipresentasikan bagi penonton oleh kelompok-kelompok musik dengan tujuan tertentu. Di dalam festival, kelompok-kelompok musik akan menampilkan komposisi terbaik di hadapan penonton dan juri. Untuk keperluan menyambut tamu undangan, peristiwa pertunjukan yang terjadi di dalamnya berbeda pula. Dewasa ini bahkan ledhug dapat tampil leluasa di festival musik event budaya lainnya. Dengan demikian, konsep pertunjukan ledhug yang dirancang dan diciptakan dengan bukan tanpa sengaja ini memiliki tujuan dan misi yang tersampaikan, yang pada akhirnya dimaknai oleh masyarakat umum.

\section{Representasi Cita-Cita}

Sebelum adanya kesneian ledhug, masyarakat Magetan telah memiliki tradisi sendiri dalam menyambut datangnya tahun baru Saka dan Hijriyah. Anak-anak kecil biasanya merayakan pergantian tahun dengan pawai taaruf, menabuh bêdhug dan melantunkan puji-pujian nuansa Islami secara berkeliling (wawancara Suminah 2012) Masyarakat Jawa kuno, mempunyai tradisi menabuh lesung pada saat bulan penuh di malam bulan Sura (wawancara Soetardjono 2014). Di Candi Sadon, Magetan, masyarakat sekitar memperingati datangnya bulan Sura dengan membawa sesaji dan melakukan ritual di sekitar candi (Primamona 2018). Beberapa masyarakat juga melakukan ritual dengan berdiam dan berpuasa (Primamona 2018). Hal tersebut berlandaskan keyakinan dan kepercayaan, yang diwadahi oleh instansi keagamaan yang dianut.

Ledhug digagas pada saat kondisi sosial, politik, dan kebudayaan mulai terbuka dengan perubahan. Berdasarkan pengamatan dan wawancara kondisi sebelumnya tidak demikian. Terbentuknya tradisi baru ledhug tersebut berangsur-angsur dapat diterima oleh seluruh lapisan masyarakat hingga kini. Dinas Kebudayaan yang merupakan instansi kebudayaan, berperan dan bertanggung jawab atas segala bentuk aktifitas kebudayaan yang ada di Magetan. Ada tiga realitas kesadaran budayawi masyarakat yang terbentuk dan terepresentasikan melalui konsep musikal ledhug, yaitu perbedaan, kesatuan, dan identitas kedaerahan.

\section{Cita-cita Persatuan dan Kesatuan}

Ledhug merupakan sarana pemerintah dan instansi kebudayaan terkait untuk menyatukan dan mengumpulkan, mempererat kesatuan dan persatuan masyarakat berkepercayaan dan juga untuk melestarikan budaya yang ada di Magetan. Hal ini sesuai dengan Program kerja Dinas Parbudpora Bidang Kebudayaan tahun 2012 dalam menyambut tahun baru Islam 1 Muharram 1434 H, tahun baru Jawa 1 Sura 1946 Saka (Muljono 2003). Hal tersebut teraktualisasi dalam frasa-frasa berikut: “...menyatukan dan mengumpulkan, mempererat kesatuan dan persatuan masyarakat 
berkepercayaan...”. Upaya persatuan ini mungkin terjadi apabila sebelumnya ada perpecahan, gesekan atau konflik. Masyarakat berkepercayaan yang dimaksudkan oleh dinas terkait adalah masyarakat Islam dan masyarakat kejawen.

Berbicara Islam dan Jawa di sini bukan berbicara lagi soal suku dan agama ataupun persoalan identitas, tetapi lebih pada kepercayaan dan keyakinan akan nilainilai yang diwujudkan dalam kesehariannya. Hampir keseluruhan masyarakat Magetan berasal dari suku Jawa. Dalam praktiknya masyarakat Jawa di Magetan ada yang menganut aliran-aliran kepercayaan yang terhimpun dalam HPK (Himpunan Penganut Kepercayaan). Ada beberapa orang yang tidak mencantumkan agama yang dianut di kolom agama kartu identitas tersebut (wawancara Suminah 2012). Kolom agama kartu identitas menjadi penyebab kesulitan mendapat pengakuan administratif, misalnya dalam hal pencatatan perkawinan. Pada dasarnya ke-empat belas aliran kepercayaan kejawen masing-masing memiliki tata cara hidup yang berbeda-beda (wawancara Suminah 2012).

Konflik adalah suatu bentuk pertentangan alamiah yang dilakukan oleh seseorang atau kelompok yang berbeda etnik (suku bangsa, ras, agama, dan golongan), karena berbeda dalam sikap, kepercayaan, nilai atau kebutuhan (Liliweri 2005, 146). Konflik berawal karena kelompok tertentu merasa memiliki sasaran dan kepentingan tertentu, namun diliputi pemikiran, perasaan atau perbuatan yang tidak sejalan (Liliweri 2005, 146). Konflik tidak selalu terlihat di permukaan, dan Liliweri menyebutnya sebagai konflik laten.

Berdasarkan data di lapangan, ada indikasi terjadinya konflik laten. Pada saat berkunjung ke Candi Sadon, juru kunci menceritakan peristiwa yang terjadi beberapa tahun silam mengenai perusakan candi yang beraliran Hindu tersebut. Beberapa orang dalam satu kelompok yang tidak diidentifikasi identitasnya dan hal ini dibenarkan oleh sejarahwan (wawancara Soetardjono 2014). Data lain menyebutkan adanya peristiwanya penyelenggaraan malam tirakatan sebelum puncak acara prosesi andum berkah bolu rahayu. Pada awalnya dilakukan kegiatan doa bersama dalam malam tirakat tersebut. Sampai pada tanggal 13 November 2012 kegiatan doa dilakukan secara tersegmen, yaitu masyarakat Islam yang diwakili MUI pada pukul 19.30-21.00 WIB dan dilanjutkan masyarakat kejawen yang diwakili HPK pada pukul 21.30-23.00 WIB. Data pengamatan merekam kelompok-kelompok ini pada saat keduanya saling bertemu dalam ruang yang sama, yaitu mengucapkan salam dengan kedua tangan yang disatukan di depan dada. Jumlah peserta antara kedua kelompok juga sangat signifikan perbedaannya.

Identitas mengenai mayoritas dan minoritas jelas terlihat dalam kondisi ini, meski fenomena tersebut nampak pada gejala yang tidak disadari. Pada dasarnya, penyebab konflik laten dapat terjadi karena adanya stereotip-stereotip negatif yang saling direproduksi untuk memahami antar kelompok mayoritas dan minoritas (Liliweri 2005 , 101). Kelompok minoritas biasanya mendapat pengalaman unik seperti perlakuan tidak adil, misalnya melalui prasangka, diskriminasi dan segregasi (Liliweri 2005, 101). Kelompok mayoritas juga mengalami hal yang unik karena jumlahnya yang lebih besar, seperti lebih banyak mendapat peluang untuk menguasai sektor ekonomi dan politik (Liliweri 2005, 109). Selain itu hal yang paling menarik, suatu kelompok minoritas biasanya mempunyai kesadaran kelompok yang kuat dalam rasa kesatuan (Liliweri 2005, 109).

Penggabungan dua instrumen lesung dan bêdhug merepresentasikan cita-cita masyarakat akan berakhirnya konflik yang berakibat negatif dalam kelangsungan hidup masyarakat. Lesung dan bêdhug dimainkan bersama-sama, di dalam satu kesatuan di 
atas panggung terbuka yang dapat dinikmati khalayak umum. Lagu-lagu yang dibawakan oleh masing-masing kelompok pun cenderung memilih genre yang dikenal oleh seluruh lapisan masyarakat seperti campursari, lagu lokal dan langgam. Dalam hal selera berkesenian, seolah-olah masyarakat itu merdeka dan bebas dari diskriminasi identitas. Nilai-nilai persatuan, rasa persaudaraan, dan rasa saling memiliki yang disisipkan inilah yang dibangun di dalam konsep pertunjukan ledhug.

\section{Mengontrol Perbedaan dalam Bahasa Musikal}

Pada sub-bab sebelumnya, terlah dipaparkan sebagian dari bentuk konflik laten yang terjadi. Hal ini sesuatu yang lazim dalam dinamika kebudayaan di berbagai wilayah di Indonesia bahkan dunia, sehingga mengekplanasinya bukanlah hal kesengajaan untuk menyinggung atau mendiskreditkan suatu agama atau paham tertentu. Hal menyangkut paham atau keagamaan dianggap sebagai sesuatu yang sangat sensistif atau tabu untuk dibicarakan. Memahami fenomena ini sebagai suatu pemaknaan khusus adalah jalan tengahnya. Misalnya melihat konflik laten sebagai momentum tepat bagi kesenian untuk melakukan keajaibannya.

Dalam pemaparan sebelumnya diungkapkan bahwa terdapat pemaknaan khusus sehingga masyarakat memberi nama Lesung Sura dan Bêdhug Muharram pada lesung dan bêdhug dalam komposisi musikal ledhug. Bagaimanapun giatnya usaha penggabungan keduanya, sinkretisme tidak serta merta terjadi. Perbedaan adalah sebuah keniscayaan. Maka Simatupang menyatakan, "Perbedaan membuat perputaran atau pergerakan sebagaimana mestinya. Perbedaan suhu akan mengakibatkan pergerakan udara, perbedaan tinggi rendah permukaan darat mengakibatkan air dapat mengalir, dan sebagainya" (Simatupang 1999, 3). Perbedaan sebaiknya dijaga. Orang Jawa memiliki cara tersendiri untuk bersikap terhadap adanya perbedaan dan konflik. Hal ini dilatarbelakangi pola kebudayaan Jawa yang sifatnya yang hirarkis, paternalistik dan feodalistik (Muluk dan Murniati 2007, 168). Beberapa ajaran Raden Mas Pandji Sosrokartono yang terkenal antara lain: catur mukti, sekti tanpo aji, ngeluruk tanpa bala, menang tan ngasorake, dan mikul dhuwur mendem jero (Wirawan 2013, 21-22).

"Kepatuhan (memendam konflik, seperti dalam ungkapan; Menhem jero) dan anti penyimpangan merupakan sikap dasar dari setiap warga. Atas nama kerukunan, orang jawa berusaha untuk menghilangkan tanda-tanda ketegangan masyarakat atau antara pribadi (ungkapan Menang tanpa ngasorake, misalnya), sehingga hubungan sosial tampak tetap harmonis dan baik, meskipun harmonis itu relatif sifatnya. Biasanya mereka akan menghidarkan konflik dengan cara membiarkan permasalahan itu berlalu atau dibatinkan." (Muluk dan Murniati 2007, 169)

Di dalam sebuah komposisi, apabila perbedaan di dalam realitas sosial yang nyata dijawab dengan bahasa musikal, maka dapat diinterpretasi bahwa lesung dan bedhug memegang peran yang sama, yaitu sebagai instrumen perkusif yang mengontrol lakunya irama. Strata keduanya sama. Di dalam komposisi keduanya saling memainkan bagiannya masing-masing sehingga komposisi memiliki tekstur. Dengan demikian, perbedaan pada hal ini dirayakan dan dkontrol dengan bahasa musikal sebagai upaya dari kepatuhan masyarakat Jawa pada umumnya.

\section{Persatuan dan Identitas Kedaerahan}

Persatuan dua paham yang sama-sama memiliki eksistensi di dalam masyarakat memang tidak dimungkinkan. Namun, di dalam konsep pertunjukan, persatuan lesung 
yang mewakili budaya Jawa dan bedhug yang mewakili budaya Islam, melahirkan suatu identitas baru yang menimbulkan rasa kepemilikan komunal. Ledhug merupakan milik seluruh masyarakat tanpa memandang bulu.

Menurut panitia penyelenggara, penghargaan atau hadiah, tata panggung dan lain sebagainya adalah cara untuk menanamkan kecintaan masyarakat Magetan, terutama kalangan muda-mudi, terhadap ledhug (wawancara Suminah 2012). Beberapa masyarakat generasi lama bernostalgia, dan bahkan ada yang terharu karena rekaman masa lalunya terpanggil kembali saat menonton pertunjukan ledhug ini. Dalam rangka pelestarian dan pengembangan, musik ledhug juga bertujuan untuk mencitrakan identitas budaya musik Magetan ke Indonesia dan bahkan dunia.

Kehidupan sosial-budaya di Magetan berbeda dengan kota-kota besar lainnya. Keberadaan event-event pertunjukan musik pun jarang yang dilaksanakan secara masif dan besar. Jika ada, maka kepentingannyapun terbatas sehingga apresiasi masyarakat muda juga terbatas. Di samping itu, pertunjukan kesenian wayang kulit dan campursari hingga saat ini masih menjadi kesenian primadona di Magetan. Tidak seperti di Solo yang hampir di setiap sudut kota, pertunjukan musik ada di berbagai ruang publik. Dengan demikian, panggung pertunjukan ledhug memiliki posisi strategis yang dapat mengarahkan masyarakatnya bertindak sesuai pesan yang tersirat di dalamnya.

\section{Simpulan}

Ledhug di dalam sebuah pertunjukan, secara implisit mengandung konsep pemahaman Jawa dan pemahaman Islam. Pemahaman itu bukan hanya hadir dalam identifikasinya sebagai musik yang pada umumnya mengandung unsur-unsur seperti: melodi, ritme, harmoni dan lain sebagainya, tetapi juga pembentukan citra di dalam benak masyarakatnya melalui manifestasi simbol-simbol ritual yang terencana. Perpaduan beberapa konsep paham tersebut adalah salah satu contoh representasi dari sinkretisme yang terus berjalan dalam kehidupan masyarakat di Nusantara. Bagaimanapun, sinkretisme musik yang terdapat pada musik ledhug di Magetan merupakan bukti bahwa musik melalui bahasa simboliknya mampu menyampaikan pesan toleransi dan perdamaian.

\section{Daftar Pustaka}

Djohan. 2009. Psikologi Musik. Yogyakarta: Penerbit Best Publisher. 2009.

Hoed, Benny H. 2011. Semiotik dan Dinamika Sosial Budaya. Depok: Komunitas Bambu.

Koentjaraningrat. 1990. Pengantar ilmu antropologi. Penerbit Pt Rineka Cipta.

Liliweri, Alo. 2005. Prasangka dan Konflik; Komunikasi Lintas Budaya Masyarakat Multikultur. LKIS Pelangi Aksara.

Merriam, Alan P. 1964. The Anthropology of Music. Northwestern University Press.

Muljono, Saleh. 2003. "Panduan Program Penyelenggaraan Kegiatan Lesung Suro - Bedhug Muharram (Ledhug) tahun 1936 Jw/ 1424 H Kabupaten Magetan 1-5 Maret 2003."

Muluk, Hamdi, dan J Murniati. 2007. "Konsep kesehatan mental menurut masyarakat etnik Jawa dan Minangkabau." Jurnal Konsep Sehat Mental 13 (2).

"Pedoman Pelaksanaan (Domlak) Festival Musik Lesung dan Bedhug dalam Rangka 1 Suro 1946 tahun Saka - 1 Muharram 1434 H Kabupaten Magetan Tahun 2012.” 2012. Kabupaten Magetan.

Peters, J.E.E., dan ASEAN Committee on Culture and Information. 2003. Sonic Orders in ASEAN Musics: A Field and Laboratory Study of Musical Cultures and Systems in Southeast Asia. Sonic Orders in ASEAN Musics: A Field and Laboratory Study of Musical Cultures and Systems in Southeast Asia. ASEAN Committee on Culture and 
Information. https://books.google.co.id/books?id=qyD8yN_Vzf4C.

Primamona, Dea Lunny. 2018. Menantimu Sura (Ledhug Sura - Lesung dan Bedhug Sura di Magetan). https://www.youtube.com/watch?v=mNhQjTlJVZw.

Saksono, Ign. Gatut, dan Joko Wicoyo. 2019. Sinkretisme Jawa: Usaha Mengolah Unsur-unsur yang Ada dan Memunculkan Satu Budaya Baru. http://psbsekolah.kemdikbud.go.id/kamaya/index.php?p=show_detail\&id=158002.

Simatupang, GR Lono Lastoro. 1999. Budaya sebagai strategi dan strategi budaya. Masyarakat Seni Pertunjukan Indonesia.

Sulisto, Ragil. 1996. Organologi Sebagai Materi Kuliah di STSI.

Sunoto. 2017. "Lingga Yoni Jejak Peradaban Masyarakat (Jawa, Bali) dari Perspektif Positivistik." Bahasa dan Seni: Jurnal Bahasa, Sastra, Seni dan Pengajarannya 45 (2): 155-69. https://doi.org/10.17977/um015v45i22017p155.

Wade, Bonnie C. 2004. Thinking musically: Experiencing music, expressing culture. Oxford University Press New York.

Wirawan. 2013. Konflik dan Manajemen Konflik: Teori, Aplikasi, dan Penelitian. Jakarta: Salemba Humanika.

\section{Biografi}

Dea Lunny Primamona S.Sn., lahir di Surabaya pada 4 Maret 1992. Memulai dunia seni musik sejak umur enam tahun. Ia pernah beberapa kali menjuarai ajang kontes bernyanyi solo, vocal group, dan paduan suara. Ia sempat memiliki passion lain di bidang seni rupa hingga membawanya menjadi karikaturnis di majalah SMA tahun 2007-2010. Selain itu, karya sketsanya pernah dipublish di www.sketchathon.com pada tahun 2017. Ia memulai pendidikan tinggi di Institut Seni Indonesia Surakarta di bidang Etnomusikologi pada tahun 2010, dan mengikuti pertukaran mahasiswa di Thammasat University Bangkok di bidang Journalism and Mass Communication pada tahun 2013. Semasa kuliah, ia aktif menulis di kolom akademia koran Joglosemar; memiliki komunitas musik etnis wanita; menjadi mahasiswa berprestasi; dan melahirkan karya feature Etnomusikologi yang pernah diputar dalam beberapa event di Surakarta. Ia menjadi pelatih dan guru musik, di instansi-instansi pendidikan formal dan nonformal. Pada tahun 2017 ia menjadi salah satu awardee Lembaga Pengelola Dana Pendidikan, mengikuti program-program yang diberikan dan melahirkan sebuah karya lagu angkatan ke-113 LPDP yang berjudul "Manunggaling Ksatria". Kini ia tengah fokus menyelesaikan pendidikan S-2 Penciptaan dan Pengkajian Seni ISI Surakarta dan aktif di komunitas-komunitas seni di Surakarta.

Dolly Nofer S. Sn., M. Sos., lahir di Padang pada 16 November 1986. Ia memulai dunia kesenian sejak sekitar tahun 2000an. Ia lebih dikenal sebagai pemusik alat tiup etnis di lingkungan seniman, dan aktif tampil di beberapa event bertaraf Nasional dan Internasional. Ia merupakan lulusan sarjana seni di bidang Etnomusikologi Institut Seni Indonesia Surakarta dan pada tugas akhir ia mengkaji "Karakteristik Sistem Musik Dendang Sawir Sutan Mudo". Kemudian Ia melanjutkan pendidikan di Universitas Negeri Sebelas Maret di bidang Kajian Budaya pada tahun 2016, dan menjadi awardee Beasiswa Unggulan Kemendikbud. Beberapa karya tulisnya antara lain: (1) "The Hybrid Identity on Music: a Study of Musical Fact in Talempong Goyang Ensamble at Minangkabau-West Sumatera" yang dipublikasikan di AJAST Journal Vol. 2 issue-2 tahun 2018; (2) "Bukan Musik Biasa (BMB): Breaking Down the Logocentrism in Music" yang dipublikasikan di Proceedings International Conference on English Literary Studies and Cultural Studies (ICELSCS) tahun 2018; (3) karya tesis yang berjudul "Diskursus Kebebasan Bermusik dalam Forum Musik dan Dialog BMB ('Bukan Musik Biasa'); dan dalam proses publikasi (4) artikel yang berjudul "Nomad Culture in the Battle of Indonesian Music Industry Discourse, Case Study: Boy-Girl Band”. 